OPEN ACCESS

Edited by:

Jose Antonio Castro-Rodriguez, Pontificia Universidad Católica de

Chile, Chile

Reviewed by:

Juraj Mokry,

Comenius University, Slovakia Yasemin Gokdemir,

Marmara University, Turkey

*Correspondence:

Mariëlle W. Pijnenburg m.pijnenburg@erasmusmc.nl

Specialty section:

This article was submitted to Pediatric Pulmonology,

a section of the journal

Frontiers in Pediatrics

Received: 17 December 2018 Accepted: 01 February 2019

Published: 21 February 2019

Citation:

Pijnenburg MW (2019) The Role of FeNO in Predicting Asthma.

Front. Pediatr. 7:41.

doi: 10.3389/fped.2019.00041

\section{The Role of FeNO in Predicting Asthma}

\author{
Mariëlle W. Pijnenburg* \\ Division of Respiratory Medicine and Allergology, Department of Pediatrics, Erasmus MC-Sophia, University Medical Center \\ Rotterdam, Rotterdam, Netherlands
}

Asthma-like symptoms like wheezing and dyspnea affect 1 in every 3 preschool children. An easily available biomarker that predicts later asthma or unfavorable lung growth in these children may be helpful in targeting the right child with the right drugs and avoiding exposure to potentially harmful drugs in others. The fraction of exhaled nitric oxide (FeNO) has been suggested as a marker of eosinophilic inflammation. FeNO can be measured in a standardized way from the age of 4 but several methods have been developed to measure FeNO also in younger children. Several studies have assessed the predictive value of FeNO in preschool wheezing children for asthma later in life. These studies have shown that FeNO may be helpful in defining different preschool wheezing phenotypes, and in assessing the risk of later asthma or impaired lung growth. However, data are conflicting on the added value over clinical parameters. In two studies in school children, high FeNO was predictive for asthma development during follow up and also predicted lower lung function growth. In school children with respiratory symptoms suggestive of asthma, particularly in atopic children, FeNO has diagnostic value for an asthma diagnosis, mostly for ruling in asthma. There are not enough data to assess if FeNO has a predictive value for lung development in school children.

Keywords: exhaled nitric oxide, preschool children, asthma, diagnosis, prediction, lung growth

\section{INTRODUCTION}

Asthma is the most prevalent chronic disorder in the western world affecting $5-15 \%$ of all school aged children and most of them have their first respiratory symptoms before they turn $5(1,2)$. Asthma-like symptoms like wheezing and dyspnea are even more frequent in preschool children with 1 in every 3 children having at least 1 wheezing episode before the age of 4 (3). Only a minority of these preschool children will develop asthma later in life and may benefit from early treatment with controller therapy to prevent symptoms and exacerbations (4). However, some of them, in particular children with severe wheezing exacerbations during the preschool years, have a lower lung function already at age 5 or $6(5,6)$. As lung function tracks during life, it is important to identify children at risk for developing asthma, impaired lung growth, and/or early decline in lung function as early as possible (7). Although the natural course of asthma cannot be altered by asthma medications such as the inhaled corticosteroids (ICS), symptoms can be reduced and lung function possibly maintained while on ICS $(8,9)$. Therefore, an easily available non-invasive biomarker that predicts later asthma in preschool children may be helpful in targeting the right child with the right drugs and avoiding exposure to potentially harmful drugs in others. 
The fraction of exhaled nitric oxide (FeNO), has been suggested as a non-invasive biomarker of (mostly eosinophilic) inflammation (10). In atopic asthmatic children, there is a moderate to goodcorrelation between FeNO and eosinophil counts in blood, induced sputum or broncho-alveolar lavage fluid (10-12). In preschool children elevated blood eosinophils have been associated with the development of later asthma suggesting that blood esoinophils may be an easy biomarker for later asthma $(13,14)$.

FeNO can be measured in a standardized way with an online single breath technique with constant expiratory flow, with increasing success rates of $40 \%$ at age 4 to almost $100 \%$ at age $10(15,16)$. Unfortunately, in preschool children the single breath technique is not feasible and alternative techniques have been developed for FeNO measurement (15). The tidal breathing offline method, with collection of exhaled air via a facemask in an appropriate reservoir for later analysis, is the most simple, is feasible in almost all children and shows good within-subject reproducibility $(17,18)$. The disadvantages of this technique are that expiratory flow is not controlled, while FeNO is highly flow-dependent, and that contamination with high concentrations of NO produced in the nasal cavity cannot be avoided. The latter can be solved by exhaling against a resistance and with a septum in the facemask, separating air from the upper and lower airways. A modification of the online single breath technique is to measure FeNO during a (raised volume) rapid thoracic compression maneuver at the end-expiratory plateau phase of the NO profile (19). This technique requires sedation and highly trained personnel. Alternatively, in children who do accept a mouthpiece manual adjustment of the expiratory flow or the use of dynamic flow restrictors may allow for a single breath, flow-controlled exhalation $(20,21)$.

Newer technology with fast-response chemiluminescence analyzers and flow control devices, may make it feasible to measure FeNO with a single breath technique in children as young as 3 years (22). Also, with mathematical algorithms single breath constant flow values may be derived from tidal breathing FeNO values (23). For now, the offline tidal breathing technique with a mask separating mouth and nose seems the most simple method to measure FeNO in preschool children.

\section{Predicting Asthma With FeNO}

Several studies assessed FeNO in preschool children. Higher FeNO values were found in young children with (recurrent) wheezing compared to healthy preschool children (19, 24-26), children with frequent wheezing with high vs. low asthma predictive index (API) $(27,28)$ and in children with persistent wheezing vs. transient wheezing (29). These studies were mainly cross sectional and compared two groups of children. Although these studies suggest that FeNO may help to phenotype young wheezing children, only few studies assessed the predictive value of FeNO in the preschool years for later asthma.

In a study in almost 400 children with lower airway symptoms, Singer et al. measured FeNO offline with a tidal breathing technique at a mean age of 22 months, and modified the classical
API by including FeNO $>10 \mathrm{ppb}$ as a major criterion and changing blood eosinophils $>4 \%$ from major to minor criterion (30). At school age, a doctor's diagnosis of asthma was based on standardized interviews. Children with asthma at school age had higher FeNO levels compared to children without asthma at that age (10.5 vs. $6.2 \mathrm{ppb} ; P<0.001)$. The new API including FeNO had a positive predictive value of $58 \%$ and a negative predictive value of $78 \%$ for later asthma, which was actually comparable to the classical API.

Caudri et al. studied the predictive value of FeNO, specific IgE and airway resistance as measured with the interrupter technique (Rint) in 3-4 year old children with wheezing symptoms (31). Both FeNO and specific IgE were associated with asthma at 8 years, also after mutual adjustment and adjustment for clinical history. In other words, FeNO had an additive predictive value over specific $\operatorname{IgE}$ and also over the clinical history (asthmatic mother, wheezing frequency and eczema). This study showed that even though FeNO and specific IgE are correlated, FeNO does not merely reflect atopy.

A cross sectional study from Denmark showed low feasibility of online single-breath FeNO measurements ranging from 0 to $71 \%$ in children of 3 to 6 years old, respectively (32). In this study FeNO $>11.5$ ppb had low sensitivity but high specificity (93\%) for an asthma diagnosis.

In unselected newborns FeNO before any respiratory symptom occurred was not associated with asthma at school age, suggesting that environmental factors are needed to induce NO production (33). However, in a longitudinal study in 116 high-risk children with eczema, Chang and co-workers found increased FeNO levels before any wheezing illness in children who had asthma and increased airway reactivity at age 5 (34). A steeper increase in FeNO was seen in children with asthma at age 5 compared to children without asthma at that age, which is in line with the hypothesis that environmental factors are needed to induce iNOS and that there might be a window of opportunity in the preschool years.

In a longitudinal cohort of 42 preschool children (6-24 months old) with recurrent wheezing FeNO $\geq 30 \mathrm{ppb}$ as assessed with a single breath technique during the raised volume rapid thoracic compression technique had a high predictive value for persisting wheezing at age 3 (area under the receiver operating curve, AUC 0.86) (35). This predictive value was better than that of the API. What is more, FeNO $\geq 30 \mathrm{ppb}$ but also tidal-FENO $\geq 7 \mathrm{ppb}$ was associated with a decline in $\mathrm{FEV}_{0.5}$ and $\mathrm{FEF}_{25-75}$ between inclusion and age 3 years. While using the same single breath technique, the same group, showed that a $10 \mathrm{ppb}$ increase in FeNO was associated with a $0.4 \mathrm{z}$-score decline in $\mathrm{FEV}_{0.5}$, a $0.4 \mathrm{z}$-score decline in $\mathrm{FEF}_{25-75}$, and a $0.42 \mathrm{z}$-score decline in $\mathrm{FEF}_{75} 6$ months later (36). FeNO also predicted wheezing exacerbations in the 6 months following measurement (AUC 0.83, 95\% CI: 0.69-0.96). However, measuring single breath FeNO in infants and preschool children is challenging, requires well-trained personnel and is only feasible in research settings.

Klaassen et al. assessed if a change in FeNO after 8 weeks of inhaled corticosteroids in preschool children predicted asthma at school age but this was not the case (37). 
It is important to realize that cut off values and predictive values of FeNO may differ between the studies due to different measurement techniques.

In school children only 2 studies have been published examining the predictive value of FeNO for the development of asthma. A study in more than 2,000 asthma-free school children (aged 7-10 years) assessed if FeNO could predict asthma development during 3 years follow up. The authors showed that children in the highest FeNO quartile had more than a 2 -fold increased risk of new-onset asthma compared to those with the lowest quartile (hazard ratio 2.1, 95\% CI 1.33.5). This effect was most notable in children with a negative parental history of asthma and did not vary with a history of allergic rhinitis (38). In a smaller study 109 children with allergic rhinitis (mean age 8.4 years, range 7-13) were followed for 5 years when they were evaluated for an asthma diagnosis (39). Children with FeNO > $35 \mathrm{ppb}$ at baseline had a higher risk of developing asthma when compared to children with lower FeNO values (OR 2.49, $P<0.01$ ) and every $10 \mathrm{ppb}$ increase above this cutoff doubled the risk of asthma further. Also, children with FeNO > $35 \mathrm{ppb}$ had a decrease in $\mathrm{FEV}_{1}$ and FVC while in the children with FeNO $<35 \mathrm{ppb} \mathrm{FEV}_{1}$ and FVC increased, suggesting less lung growth in children with high FeNO values.

In summary, the studies mentioned here have shown that FeNO may be helpful in objectively defining different wheezing phenotypes in preschool children, and assessing the risk of asthma or impaired lung growth later in life. Preschool children with increased FeNO levels have an increased risk of later asthma. Data are conflicting on the added value over clinical parameters. In two studies in school children, high FeNO was predictive for asthma development during follow up and also predicted lower lung function growth.

\section{FeNO in the Diagnosis of Asthma in School Children}

In children only few studies assessed the value of FeNO for diagnosing asthma (40-42). Woo et al. included 245 steroid-naïve children with respiratory symptoms suggestive of asthma. Asthma was diagnosed in 167 of them, based on symptoms and $\geq 12 \%$ bronchodilator response and/or airway hyperresponsiveness as assessed with methacholine provocation (40). The negative and positive predictive values of $\mathrm{FeNO}$ at a cutoff of $22 \mathrm{ppb}$ for an asthma diagnosis were 90.5 and $48.6 \%$, respectively. FeNO performed better as a diagnostic test in the atopic children (AUC 0.85, 95\% CI 0.79-0.90) if compared to atopic and non-atopic children all together (AUC 0.76; 95\% CI 0.70-0.82). In a study from Israel in 150 children who were referred with respiratory symptoms, FeNO, sputum eosinophils and $\mathrm{FEV}_{1}$ were assessed at baseline. During the following 18 months asthma was diagnosed based on wheezing exacerbations, bronchodilator response $\geq 15 \%$ and/or $\mathrm{FEV}_{1}$ variability $\geq 15 \%$ and/or a positive bronchoprovocation test (41). FeNO performed similar as sputum eosinophils for the diagnosis asthma (AUC 0.90 and 0.92 , respectively) and better than baseline $\mathrm{FEV}_{1}$. Nineteen ppb appeared the best cutoff with sensitivity of $80 \%$, specificity of
$92 \%$, positive predictive value of $89 \%$ and a negative predictive value of $86 \%$.

A third study that assessed the diagnostic value of FeNO was performed in 4-8 years old children with asthmatic symptoms. Children with recent recurrent wheeze were labeled as "probable asthma" and compared to controls. The analysis of the ROC showed that FeNO had good power for discriminating between children with probable asthma and healthy controls, with a sensitivity of $86 \%$ and specificity of $92 \%$ at the cut off level of 1.5 SD above predicted. This was better than the predictive value of lung function and bronchodilator response as assessed with impulse oscillometry (42).

A real-life retrospective study in 3,612 children with symptoms suggestive of asthma showed poor predictive value of FeNO $>15.8 \mathrm{ppb}$ for an asthma diagnosis with an area under the ROC curve of only 0.53 (43).

In an unselected population of 1,602 children, questionnaires, spirometry with bronchodilator response and FeNO were assessed. Asthma was defined as symptoms suggestive of asthma with reported medical diagnosis or evidence of bronchodilator response. FeNO had poor predictive value (area under the ROC curve 0.62) (44). This poor predictive value may be explained by the fact that unselected children were included, in contrast to most studies that included children with respiratory symptoms.

In general, FeNO has diagnostic value for an asthma diagnosis, in particular in children with respiratory symptoms and in atopic children and mostly ruling in asthma. The National Institute for Health and Care Excellence (NICE) recommends measuring FeNO as a diagnostic tool in adults and children who have an intermediate probability of having asthma and in combination with other diagnostic options such as spirometry (45). Similarly, the British Thoracic Society guidelines recommend to use FeNO (if available) "to find evidence of eosinophilic inflammation" (46). In contrast, the 2018 GINA guidelines conclude that FENO has not been established useful for an asthma diagnosis (4).

\section{FeNO in Predicting Lung Function Decline}

Several recent studies showed that high baseline FeNO was associated with reduced lung function growth in asthmatic children (47) and accelerated lung function decline in adults $(48,49)$. In the pediatric study from China 193 asthmatic children, mean age 9.7 years (SD 1.9 years) were followed for 5 years (47). One quarter had reduced lung function growth which was associated with lower baseline spirometry, higher FeNO and female sex. Also, two single nucleotide polymorphisms (GSDMB_rs2305480 and IL33_rs1342326) were associated with longitudinal changes in lung function.

More longitudinal studies in children are needed to assess the predictive value of FeNO for lung development.

\section{CONCLUSION}

In preschool children FeNO may be helpful in objectively discriminating between different wheezing phenotypes and in predicting asthma later in life.

Only few studies in school children assessed the diagnostic value of FeNO for an asthma diagnosis; particularly in atopic 
children with respiratory symptoms, FeNO has a high positive predictive value for an asthma diagnosis. If FeNO helps to predict lung function decline or impaired lung growth remains to be shown.

\section{AUTHOR CONTRIBUTIONS}

The author confirms being the sole contributor of this work and has approved it for publication.

\section{REFERENCES}

1. Akinbami LJ, Moorman JE, Bailey C, Zahran HS, King M, Johnson CA, et al. Trends in Asthma Prevalence, Health Care use, and Mortality in the United States, 2001-2010. NCHS Data Brief (2012) 94:1-8.

2. Selroos O, Kupczyk M, Kuna P, Lacwik P, Bousquet J, Brennan D, et al. National and regional asthma programmes in Europe. Eur Respir Rev. (2015) 24:474-83. doi: 10.1183/16000617.00008114

3. Kuehni CE, Davis A, Brooke AM, Silverman M. Are all wheezing disorders in very young (preschool) children increasing in prevalence? Lancet (2001) 357:1821-5. doi: 10.1016/S0140-6736(00)04958-8

4. (2018). 2018 GINA Report, Global Strategy for Asthma Management and Prevention. Available online at: https:/ginasthma.org/wp-content/uploads/ 2018/04/wms-GINA-2018-report-V1.3-002.pdf

5. Illi S, von Mutius E, Lau S, Niggemann B, Gruber C, Wahn U, et al. (2006). Perennial allergen sensitisation early in life and chronic asthma in children: a birth cohort study. Lancet 368:763-70. doi: 10.1016/S0140-6736(06)69286-6

6. O'Brian AL, Lemanske RF, Evans MD, Gangnon RE, Jackson D, Jackson J, et al. (2012). Recurrent severe exacerbations in early life and reduced lung function at school age. J Allergy Clin Immunol. 129:1162-4. doi: 10.1016/j.jaci.2011.11.046

7. McGeachie MJ, Yates KP, Zhou X, Guo F, Sternberg AL, Strunk RC, et al. (2016). Patterns of growth and decline in lung function in persistent childhood asthma. N Engl J Med. 374:1842-52. doi: 10.1056/NEJMoa1513737

8. Guilbert TW, Morgan WJ, Zeiger RS, Mauger DT, Boehmer SJ, Martinez FD, et al. Long-term inhaled corticosteroids in preschool children at high risk for asthma. N Engl J Med. (2006) 354:1985-97. doi: 10.1056/NEJMoa051378

9. Murray CS, Woodcock A, Langley SJ, Morris J, Custovic A. Secondary prevention of asthma by the use of Inhaled Fluticasone propionate in Wheezy INfants (IFWIN): double-blind, randomised, controlled study. Lancet (2006) 368:754-62. doi: 10.1016/S0140-6736(06)69285-4

10. Pijnenburg MW, De Jongste JC. Exhaled nitric oxide in childhood asthma: a review. Clin Exp Allergy (2008) 38:246-59. doi: 10.1111/j.1365-2222.2007.02897.x

11. Fleming L, Tsartsali L, Wilson N, Regamey N, Bush A. Longitudinal relationship between sputum eosinophils and exhaled nitric oxide in children with asthma. Am J Respir Crit Care Med. (2013) 188:400-2. doi: 10.1164/rccm.201212-2156LE

12. Pedroletti C, Lundahl J, Alving K, Hedlin G. Exhaled nitric oxide in asthmatic children and adolescents after nasal allergen challenge. Pediatr Allergy Immunol. (2005) 16:59-64. doi: 10.1111/j.1399-3038.2005.00200.x

13. Gaillard EA, McNamara PS, Murray CS, Pavord ID, Shields MD. Blood eosinophils as a marker of likely corticosteroid response in children with preschool wheeze: time for an eosinophil guided clinical trial? Clin Exp Allergy (2015) 45:1384-95. doi: 10.1111/cea.12535

14. Wandalsen GF, Solé D, Bacharier LB. Identification of infants and preschool children at risk for asthma: predictive scores and biomarkers. Curr Opin Allergy Clin Immunol. (2016) 16:120-6. doi: 10.1097/ACI.00000000000 00240

15. American Thoracic S, and European Respiratory S. ATS/ERS recommendations for standardized procedures for the online and offline measurement of exhaled lower respiratory nitric oxide and nasal nitric oxide, 2005. Am J Respir Crit Care Med. (2005) 171:912-30. doi: 10.1164/rccm.200406-710ST

16. Buchvald F, Baraldi E, Carraro S, Gaston B, De Jongste J, Pijnenburg M, et al. Measurements of exhaled nitric oxide in healthy subjects age 4 to 17 years. J Allergy Clin Immunol. (2005) 115:1130-6. doi: 10.1016/j.jaci.2005. 03.020
17. Silkoff PE, Stevens A, Pak J, Bucher-Bartelson B, Martin RJ. A method for the standardized offline collection of exhaled nitric oxide. Chest (1999) 116:754-9. doi: $10.1378 /$ chest.116.3.754

18. van der Heijden HH, Brouwer ML, Hoekstra FP, van der Pol P, Merkus J. Reference values of exhaled nitric oxide in healthy children 1-5 years using off-line tidal breathing. Pediatr Pulmonol. (2014) 49:291-5. doi: $10.1002 /$ ppul.22796

19. Wildhaber JH, Hall GL, Stick SM. Measurements of exhaled nitric oxide with the single-breath technique and positive expiratory pressure in infants. Am J Respir Crit Care Med. (1999) 159:74-8. doi: 10.1164/ajrccm.159.1.9805021

20. Baraldi E, Scollo M, Zaramella C, Zanconato S, Zacchello F. A simple flow-driven method for online measurement of exhaled NO starting at the age of 4 to 5 years. Am J Respir Crit Care Med. (2000) 162:1828-32. doi: 10.1164/ajrccm.162.5.2002014

21. Pijnenburg MW, Lissenberg ET, Hofhuis W, Ghiro L, Ho WC, de Jongste JC, et al. Exhaled nitric oxide measurements with dynamic flow restriction in children aged 4-8 yrs. Eur Respir J. (2002) 20:919-24. doi: 10.1183/09031936.02.01282002

22. Heijkenskjold-Rentzhog C, Kalm-Stephens P, Nordvall L, Malinovschi A, Alving K. "New method for single-breath fraction of exhaled nitric oxide measurement with improved feasibility in preschool children with asthma. Pediatr Allergy Immunol. (2015) 26:662-7. doi: 10.1111/pai.12447

23. van Mastrigt E, de Groot RC, van Kesteren HW, Vink AT, de Jongste JC, Pijnenburg MW. Tidal breathing FeNO measurements: a new algorithm. Pediatr Pulmonol. (2014) 49:15-20. doi: 10.1002/ppul.22782

24. Baraldi E, Dario C, Ongaro R, Scollo M, Azzolin NM, Zacchello F, et al. Exhaled nitric oxide concentrations during treatment of wheezing exacerbation in infants and young children. Am J Respir Crit Care Med. (1999) 159(4 Pt 1):1284-8. doi: 10.1164/ajrccm.159.4.9807084

25. Sayao LB, de Britto MC, Burity E, Rattes C, Reinaux CM, de AndradeD, et al. Exhaled nitric oxide as a diagnostic tool for wheezing in preschool children: a diagnostic accuracy study. Respir Med. (2016) 113:15-21. doi: 10.1016/j.rmed.2016.02.008

26. Soh JE, Kim KM, Kwon JW, Kim HY, Seo JH, Shim JY, et al. Recurrent wheeze and its relationship with lung function and airway inflammation in preschool children: a cross-sectional study in South Korea. BMJ Open (2017) 7:e018010. doi: 10.1136/bmjopen-2017-018010

27. Moeller A, Diefenbacher C, Lehmann A, Rochat M, Brooks-Wildhaber J, Hall $\mathrm{G}$, et al. Exhaled nitric oxide distinguishes between subgroups of preschool children with respiratory symptoms. J Allergy Clin Immunol. (2008) 121:7059. doi: 10.1016/j.jaci.2007.11.008

28. Castro-Rodriguez JA, Sardon O, Perez-Yarza EG, Korta J, Aldasoro A, Mintegui J, et al. Young infants with recurrent wheezing and positive asthma predictive index have higher levels of exhaled nitric oxide. J Asthma (2013) 50:162-5. doi: 10.3109/02770903.2012.754030

29. Oh MA, Shim JY, Jung YH, Seo JH, Young Kim H, Hong SJ, et al. Fraction of exhaled nitric oxide and wheezing phenotypes in preschool children. Pediatr Pulmonol. (2013) 48:563-70. doi: 10.1002/ppul.22705

30. Singer F, Luchsinger I, Inci D, Knauer N, Latzin P, Wildhaber J, et al. Exhaled nitric oxide in symptomatic children at preschool age predicts later asthma. Allergy (2013) 68:531-8. doi: 10.1111/all.12127

31. Caudri D, Wijga AH, Hoekstra MO, Kerkhof M, Koppelman GH, et al. Prediction of asthma in symptomatic preschool children using exhaled nitric oxide, Rint and specific IgE. Thorax (2010) 65:801-7. doi: 10.1136/thx.2009.126912

32. Vilmann L, Buchvald F, Green K, Nielsen KG. Fractional exhaled nitric oxide and multiple breath nitrogen washout in preschool healthy and asthmatic children. Respir Med. (2017) 133:42-7. doi: 10.1016/j.rmed.2017.10.027 
33. Usemann J, Fuchs O, Anagnostopoulou P, Korten I, Gorlanova O, Roosli M, et al. Predictive value of exhaled nitric oxide in healthy infants for asthma at school age. Eur Respir J. (2016) 48:925-8. doi: 10.1183/13993003.00439-2016

34. Chang D, Yao W, Tiller CJ, Kisling J, Slaven JE, Tepper RS, et al. Exhaled nitric oxide during infancy as a risk factor for asthma and airway hyperreactivity. Eur Respir J. (2015) 45:98-106. doi: 10.1183/09031936.00034614

35. Elliott M, Heltshe SL, Stamey DC, Cochrane ES, Redding GJ, Debley JS, Exhaled nitric oxide predicts persistence of wheezing, exacerbations, and decline in lung function in wheezy infants and toddlers. Clin Exp Allergy (2013) 43:1351-61. doi: 10.1111/cea.12171

36. Debley JS, Stamey DC, Cochrane ES, Gama KL, Redding GJ. Exhaled nitric oxide, lung function, and exacerbations in wheezy infants and toddlers. J Allergy Clin Immunol. (2010) 125:e1213. doi: 10.1016/j.jaci.2010. 03.023

37. Klaassen EM, van de Kant KD, Jobsis Q, Hovig ST, van Schayck CP, Dompeling E, et al. Symptoms, but not a biomarker response to inhaled corticosteroids, predict asthma in preschool children with recurrent wheeze. Med Inflamm. (2012) 2012:162571. doi: 10.1155/2012/1 62571

38. Linn WS, Rappaport EB, Berhane KT, Bastain TM, Avol EL, Gilliland FD. Exhaled nitric oxide in a population-based study of southern California schoolchildren. Respir Res. (2009) 10:28. doi: 10.1186/1465-9921-10-28

39. Di Cara G, Marcucci F, Palomba A, Milioni M, Pecoraro L, Ciprandi G, et al. Exhaled nitric oxide in children with allergic rhinitis: a potential biomarker of asthma development. Pediatr Allergy Immunol. (2015) 26:85-7. doi: $10.1111 /$ pai.12326

40. Woo SI, Lee JH, Kim H, Kang JW, Sun YH, Hahn YS. Utility of fractional exhaled nitric oxide (F(E)NO) measurements in diagnosing asthma. Respir Med. (2012) 106:1103-9. doi: 10.1016/j.rmed.2012.03.022

41. Sivan Y, Gadish T, Fireman E, Soferman R. The use of exhaled nitric oxide in the diagnosis of asthma in school children. J Pediatr. (2009) 155:211-6. doi: 10.1016/j.jpeds.2009.02.034

42. Malmberg LP, Pelkonen AS, Haahtela T, Turpeinen M. Exhaled nitric oxide rather than lung function distinguishes preschool children with probable asthma. Thorax (2003) 58:494-9. doi: 10.1136/thorax.58.6.494
43. Grzelewski T, Witkowski K, Makandjou-Ola E, Grzelewska A, Majak P, Jerzynska J, et al. Diagnostic value of lung function parameters and FeNO for asthma in schoolchildren in large, real-life population. Pediatr Pulmonol. (2014) 49:632-40. doi: 10.1002/ppul.22888

44. Martins C, Silva D, Severo M, Rufo J, Paciencia I, Madureira J, et al. Spirometry-adjusted fraction of exhaled nitric oxide increases accuracy for assessment of asthma control in children. Pediatr Allergy Immunol. (2017) 28:754-62. doi: 10.1111/pai.12803

45. (2000). Measuring Fractional Exhaled Nitric Oxide Concentration in Asthma: NIOX MINO, NIOX VERO and NObreath. Available online at: https://www. nice.org.uk/guidance/dg12

46. (2016). British Guideline on the Management of Asthma. Available online at: https://www.brit-thoracic.org.uk/document-library/clinical-information/ asthma/btssign-asthma-guideline-2016/

47. Leung TF, Tang MF, Leung ASY, Tam WWS, Sy HY, Wong GWK. Trajectory of spirometric and exhaled nitric oxide measurements in Chinese schoolchildren with asthma. Pediatr Allergy Immunol. (2018) 29:166-73. doi: $10.1111 /$ pai.12836

48. Matsunaga K, Hirano T, Oka A, Ito K, Edakuni N. Persistently high exhaled nitric oxide and loss of lung function in controlled asthma. Allergol Int. (2016) 65:266-71. doi: 10.1016/j.alit.2015.12.006

49. Coumou H, Westerhof GA, de Nijs SB, Zwinderman AH, Bel EH. Predictors of accelerated decline in lung function in adult-onset asthma. Eur Respir J. (2018) 51:1701785. doi: 10.1183/13993003.01785-2017

Conflict of Interest Statement: The author declares that the research was conducted in the absence of any commercial or financial relationships that could be construed as a potential conflict of interest.

Copyright (c) 2019 Pijnenburg. This is an open-access article distributed under the terms of the Creative Commons Attribution License (CC BY). The use, distribution or reproduction in other forums is permitted, provided the original author(s) and the copyright owner(s) are credited and that the original publication in this journal is cited, in accordance with accepted academic practice. No use, distribution or reproduction is permitted which does not comply with these terms. 